\title{
CONCEPÇÕES DE MODELAGEM E A PESQUISA EM SALA DE AULA NA EDUCAÇÃO MATEMÁTICA
}

\author{
Emerson Silva de Sousal \\ Isabel Cristina Machado Lara² \\ Maurivan Güntzel Ramos 3
}

\section{RESUMO}

Este artigo apresenta uma visão geral das principais concepções sobre Modelagem Matemática no contexto educacional como parte do processo de pesquisa em sala de aula. Objetiva investigar em uma abordagem teórica as convergências e divergências entre três concepções de Modelagem, e identificar o favorecimento do processo educativo pelo seu uso, levando em conta essas convergências e divergências. Para isso, são consideradas três publicações que apresentam de uma forma simplificada essas concepções. São elas: Modelagem Matemática na Educação em sua essência (BIEMBENGUT, 2014); Modelagem Matemática sob um olhar de Educação Matemática e suas implicações para a construção do conhecimento matemático em sala de aula (BURAK, 2010); e, Modelagem Matemática: O que é? Por que? Como? (BARBOSA, 2004). Identifica que as três publicações sinalizam convergência nos aspectos mais essenciais da utilização da Modelagem, propiciando assim, a integração desta com alguns aspectos da pesquisa em sala de aula, além de apontar uma aproximação das três concepções de Modelagem na Educação para um favorecimento dos processos ensino e aprendizagem de Matemática e de outras Ciências.

Palavras-chave: Modelagem Matemática. Pesquisa em Sala de Aula. Educação Matemática.

\footnotetext{
1 Doutorado (em andamento) em Educação em Ciências e Matemática pela PUC-RS. Atua como professor efetivo DE, na Universidade Federal do Oeste do Pará (UFOPA). E-mail: essousa73@gmail.com

2 Doutora em Educação pela Universidade Federal do Rio Grande do Sul. Professora permanente no Programa de Pós Graduação em Educação em Ciências e Matemática e da Faculdade de Matemática da Pontifícia Universidade Católica do Rio Grande do Sul. Email: isabel.lara@pucrs.br

3 Doutorado em Educação na Pontifícia Universidade Católica do Rio Grande do Sul. Professor titular da Pontifícia Universidade Católica do Rio Grande do Sul. E-mail: mgramos@pucrs.br
} 


\title{
CONCEPTS OF MODELING AND RESEARCH IN THE CLASSROOM IN
}

\section{MATHEMATICS EDUCATION}

\begin{abstract}
This article presents an overview of the key concepts of Mathematical Modeling in the educational context as part of the research process in the classroom. The aim is to investigate the convergences and divergences between three modeling concepts in a theoretical approach, and identify favoring the education process for its use, considering these convergences and divergences. For this, three publications are presented in a simplified form to show these conceptions. They are: Mathematical Modeling in Education in its essence (BIEMBENGUT, 2014); Mathematical Modeling under a Mathematical Education perspective and its implications for the construction of mathematical knowledge in the classroom (BURAK, 2010); and, Mathematical Modeling: What is it? Why? How? (BARBOSA, 2004). It was identified that the three publications indicate convergence on the most important aspects of working with modeling, thus enabling the integration of this with some aspects of research in the classroom, while pointing out an approximation of the three modeling concepts in Education for favoring the teaching and learning of mathematics and other sciences.
\end{abstract}

Keywords: Mathematical Modeling. Research Classroom. Mathematics Education.

\section{CONCEPCIONES DE MODELAJE Y LA INVESTIGACIÓN EN EL AULA DE EDUCACIÓN MATEMÁTICA}

\section{RESUMEN}

Modelado en el contexto educativo como parte del proceso de investigación en el aula de matemática. Tiene como objetivo investigar desde un enfoque teórico, las convergencias y divergencias entre tres concepciones de Modelado, e identificar el favoritismo en el proceso educativo para su uso, teniendo en cuenta esas convergencias y divergencias. Para ello, son consideran tres publicaciones que presentan de una forma simplificada esas concepciones. Ellas son: Modelaje Matemático en la educación en su esencia (BIEMBENGUT, 2014); Modelaje Matemático sobre una mirada de la matemática y sus implicaciones para la construcción del conocimiento matemático en el aula (BURAK, 2010); y Modelaje matemático: ¿¿Qué es? ¿Por qué? ¿̇Cómo? (BARBOSA, 2004). Identifica que las tres publicaciones indican convergencia en los aspectos más esenciales de la utilización del modelado, propiciando así, la integración de esta con algunos aspectos de la investigación en el aula, además de señalar una aproximación de los tres conceptos de modelado en la educación para favorecer los procesos de enseñanza y aprendizaje de las matemáticas y otras ciencias.

Palabras clave: Modelaje Matemático. Investigación en el Aula. Educación de las Matemáticas. 


\section{INTRODUÇÃO}

No âmbito da Educação Matemática, a Modelagem tem sido apontada como alternativa metodológica de ensino e aprendizagem. Vários modos de utilizá-la como parte do processo de pesquisa em sala de aula têm surgido para proporcionar melhor interação dos estudantes e professores envolvidos nesse processo.

De acordo com Biembengut (2009), no Brasil, a Modelagem Matemática começa a se configurar como uma prática educativa por volta do final da década de 1970 e início dos anos de 1980. Segundo a autora, no período de 1976 até 2006 são consideras três fases da concepção de Modelagem como prática educativa do ensino de Matemática no contexto da sala de aula. Na primeira fase (1976 - 1986), a Modelagem é tratada como um refazer de modelos clássicos, conforme os trabalhos produzidos e orientados por Aristides Camargo Barreto; na segunda fase (1987 - 1990), como Modelagem clássica, segundo os moldes da Matemática Aplicada, conforme os trabalhos orientados por Rodney Carlos Bassanezi; e na terceira fase (a partir de 1990), proposto por Biembengut (1990) a concepção de "Modelação", Modelagem no Ensino regular com currículo.

Desde então, outras concepções têm surgido nesse contexto. Assim, quando se pergunta o que é Modelagem Matemática, ou, como desenvolvê-la em sala de aula, não há uma resposta única, pois depende da concepção adotada. De acordo com Meyer, Caldeira e Malheiros (2011, p. 79), "pequenas sutilezas fazem com que as definições de Modelagem adotadas por diferentes pesquisadores apresentem aspectos diferenciados".

No âmbito da Educação Matemática, o número de pesquisas sobre Modelagem, tanto como método de pesquisa quanto método de ensino, vem crescendo nos últimos anos (de 1989 a 2011), conforme levantamento de produções brasileiras (teses e dissertações) feito por Bonotto e Lara (2013), e Tambarussi e Klüber $(2013,2014)$. Vários modos de utilizá-la em sala de aula têm surgido para proporcionar melhor compreensão e interação tanto dos estudantes como dos professores envolvidos nesse processo. 
Na perspectiva de Bassanezi (2002), o desenvolvimento de atividades que utilizam a Modelagem como estratégia de ensino e aprendizagem, requer 0 entendimento das etapas que direcionam o trabalho para se chegar aos objetivos propostos, possibilitando que a construção e análise de modelos faça parte desse processo. Isso ocorreria independente da concepção de Modelagem Matemática adotada.

Nessa perspectiva, encontramos várias concepções sobre sua utilização no contexto educacional. Alguns destaques brasileiros, além do professor Rodney Carlos Bassanezi, que tem sido o principal incentivador e fonte de inspiração na utilização da Modelagem como método de ensino e aprendizagem, podem ser citados, como por exemplo: Biembengut (1990, 2003, 2014); Burak (1992, 2004, 2010); Barbosa (2001, 2003, 2004); Almeida e Dias (2004); Chaves e Espírito Santo (2008); Caldeira (2009); Araújo (2009), dentre outros.

Percebe-se, no entanto, que as principais concepções de Modelagem adotadas nas publicações brasileiras, no âmbito educacional, tanto no contexto prático como teórico, são ou advém das propostas por Biembengut, Burak e Barbosa. Vale ressaltar que esses três professores tiveram influência direta do próprio professor Rodney Carlos Bassanezi, que foi orientador no mestrado de Biembengut e Burak, e co-orientador no doutorado de Barbosa.

Assim, ao querer inserir atividades de Modelagem no contexto da pesquisa em sala de aula, levantam-se as seguintes questões: Que convergências e divergências emergem na comparação entre as concepções de Biembengut, Burak e Barbosa? Levando-se em conta essas convergências e divergências, de que modo o uso de Modelagem pode favorecer os processos de ensino e aprendizagem com enfoque na pesquisa em sala de aula como princípio pedagógico?

Portanto, na tentativa de responder tais questões, será feita uma exposição dos principais pontos dessas concepções. Serão consideradas publicações desses autores que trazem uma síntese de sua concepção. São 
elas: P1) Modelagem Matemática na Educação em sua essência. (BIEMBENGUT, 2014); P2) Modelagem Matemática sob um olhar de Educação Matemática e suas implicações para a construção do conhecimento matemático em sala de aula (BURAK, 2010); e, P3) Modelagem Matemática: O que é? Por que? Como? (BARBOSA, 2004).

Vale ressaltar que os autores possuem produções mais atuais. Contudo, comungam da mesma concepção apresentada nas produções selecionadas para esta análise.

\title{
2 CONCEPÇÕES DE MODELAGEM E A PESQUISA EM SALA DE AULA
}

De acordo com Bassanezi (2002), o próprio professor precisa estar motivado no processo de ensino e aprendizagem, caso contrário, nenhuma estratégia será efetiva. O autor afirma que "[...] os professores devem valorizar o que ensinam de modo que o conhecimento seja ao mesmo tempo interessante, por ser útil, e estimulante, por ser fonte de prazer" (BASSABEZI, 2002, p. 16). Logo, a busca de uma estratégia de ensino e de aprendizagem se faz necessária, e a Modelagem Matemática, afirma ele, "tem se mostrado muito eficaz" (p. 16). O autor afirma que:

\begin{abstract}
A Modelagem Matemática consiste na arte de transformar problemas da realidade em problemas matemáticos e resolvê-los interpretando suas soluções na linguagem do mundo real. [...] pressupõe multidisciplinaridade. $E$, nesse sentido, vai ao encontro das novas tendências que apontam para a remoção de fronteiras entre as diversas áreas de pesquisa. [...] é um processo dinâmico utilizado para a obtenção e validação de modelos matemáticos (BASSANEZI, 2002, p.16).
\end{abstract}

Bassanezi (2002) destaca que a Modelagem pode ser considerada tanto como método científico para desenvolver pesquisa quanto como estratégia pedagógica de ensino e aprendizagem. Quanto a realizar pesquisa, o próprio processo de Modelagem já aponta para esse fim, como destacam Moraes, Galiazzi e Ramos (2012, p. 12): a pesquisa em sala de aula pode envolver os participantes, alunos e professores, "[...] num processo de questionamento do discurso, das verdades implícitas e explícitas nas 
formações discursivas, propiciando a partir disto a construção de argumentos que levem a novas verdades". Esses autores formulam o seguinte princípio geral, quando afirmam que a pesquisa em sala de aula

[...] pode ser compreendida como um movimento dialético, em espiral, que se inicia com o questionar dos estados do ser, fazer, e conhecer dos participantes, construindo-se a partir disso novos argumentos que possibilitam atingir novos patamares deste ser, fazer e conhecer, estágios esses então comunicados a todos os participantes do processo (MORAES; GALIAZZI; RAMOS, 2012, p. 12, grifo nosso).

Percebe-se a relação muito próxima entre Modelagem e a pesquisa em sala de aula, pois de acordo com Almeida e Silva (2015, p. 209), as atividades de modelagem têm como maior contribuição proporcionar o desenvolvimento de

[...] investigações em sala de aula, as quais têm o problema como ponto de partida, a intencionalidade na busca, a formulação de hipóteses como fatores que se colocam no caminho para indicar direções e as diferentes resoluções matemáticas são empreendidas com vistas a resolver um problema.

Cargnin-Stieler e Bisognin (2009, p. 3) reforçam essas ideias quando afirmam:

"[...] a modelagem matemática, por sua natureza, envolve uma aprendizagem significativa e contextualizada ao contemplar pesquisa e investigação, a partir de temas propostos pelos alunos e professores, em um processo de diálogo permanente".

Diante dessas considerações, e com o intuito de tentar aprofundar um pouco mais essas ideias, pretende-se abordar a seguir os principais pontos relativos às três concepções de Modelagem Matemática (Biembengut, Burak e Barbosa) no contexto educacional. Para isso, serão analisadas as publicações já mencionadas.

\section{1 (P1) - Modelagem Matemática na Educação em sua essência}

Essa publicação é um capítulo do livro Modelagem Matemática no Ensino Fundamental, de 2014, editado pela primeira vez em 1999. A autora, 
Maria Salett Biembengut (FURB) realizou graduação em Matemática (1980) e Pedagogia (1985), especialização na UNICAMP (1987), mestrado em Educação Matemática pela UNESP (1990) e doutorado em Engenharia de Produção e Sistemas pela UFSC (1997). Dedica-se à pesquisa em Educação Matemática em especial em Modelagem Matemática desde 1986.

A síntese da publicação está dividida nos seguintes questionamentos: 1) como ensinar modelagem em cursos diversos? 2) como tornar a modelagem um método de ensino? 3) como aprender para ensinar matemática por meio de modelos? 4) que possibilidades e dificuldades surgem para a implementação da modelagem na Educação?

Inicialmente, Biembengut (2014, p. 20) propõe que "[...] modelo [matemático] é um conjunto de símbolos e relações matemáticas que traduzem, de alguma forma, um fenômeno em questão". A representação de um modelo, segundo a autora, pode ser por meio de "desenho ou imagem, projeto, esquema, gráfico, lei matemática, dentre outras formas". E diz mais: "O valor do modelo vai além dos motivos de quem o modelou, mas essencialmente dos motivos daqueles que dele se servirão" (BIEMBENGUT, 2014, p. 21).

Assim, Modelagem é o "[...] processo envolvido na elaboração de modelo de qualquer área do conhecimento. Trata-se de um processo de pesquisa"(BIEMBENGUT, 2014, p. 21). Na Educação, a autora denomina a modelagem como método de ensino com pesquisa, de 'Modelação Matemática', que é o

"[...] método que se utiliza das fases do processo da modelagem na Educação formal, com a estrutura vigente: currículo, período, horário, espaço físico, número de horas-aula por período letivo, número de estudantes por classe" (BIEMBENGUT, 2014, p. 30).

Segundo a autora, a Modelação

"[...] orienta-se pelo ensino do conteúdo curricular a partir de reelaboração de modelos matemáticos aplicados em alguma área do conhecimento e, paralelamente, pela orientação dos estudantes à pesquisa" (BIEMBENGUT, 2014, p. 30). 
Nesse sentido, Biembengut (2014) defende que a Modelação possibilita aos estudantes, a partir de temas ou assuntos de seu interesse, que desenvolvam

"[...] pesquisa e, posteriormente formulem-na em linguagem matemática até chegar a um modelo (fórmula, tabela, gráfico, etc.). Modelo que permite a criação de algo ou compreensão, previsão, inferência da situação estudada" (p. 59).

Para a autora, as etapas do processo de Modelagem ou Modelação podem ser desenvolvidas em três fases: Percepção e apreensão, Compreensão e explicitação, e, Significação e expressão. Na primeira fase, a percepção ocorre no reconhecimento da situação-problema, e a apreensão, na familiarização com o assunto a ser modelado; na segunda fase, a compreensão ocorre na formulação do problema, e a explicitação, na formulação do modelo e na resolução do problema a partir do modelo; e na terceira fase, a significação ocorre na interpretação da solução e na validação do modelo (avaliação), e a expressão ocorre na divulgação do processo e do resultado (modelo).

Surge, então, o primeiro questionamento: como ensinar Modelagem em cursos diversos? De acordo com a autora, o professor que se propõe a trabalhar com Modelagem precisa ter em mente dois públicos diferentes, a saber: os que vão desenvolver uma atividade de Modelagem; e os que vão aprender para ensinar. O primeiro caso refere-se aos cursos Técnicos ou de Ensino Superior (Biologia, Engenharia, Economia etc.). Nesses, o professor precisa "[...] criar condições para que os estudantes aprendam a arte de modelar" (BIEMBENGUT, 2014, p. 29), e que aprendam a pesquisar e cheguem a um modelo aplicado à sua área de conhecimento.

O segundo caso, refere-se aos cursos de Licenciatura em Matemática e de Formação continuada. Neste, o professor pode desenvolver o trabalho de modo que os estudantes (professores e futuros professores) aprendam a "[...] usar modelagem como método de ensino de Matemática Modelação" (BIEMBENGUT, 2014, P. 30). Além disso, que também aprendam a modelar, tendo como enfoques, a pesquisa e/ou o ensino. 
O segundo questionamento é: como tornar a Modelagem um método de ensino? Então, a autora propõe a Modelação Matemática como método de ensino na Educação formal, cujo objetivo

"é promover conhecimento aos estudantes. [...] ensinar a eles fazer pesquisa e, ao mesmo tempo, ensinar os conteúdos requeridos na pesquisa em acordo com o programa curricular da disciplina" (BIEMBENGUT, 2014, p. 30).

Assim, há uma atuação em duas frentes de abordagens: o ensino, "[...] que nos permite desenvolver o conteúdo curricular e, ao mesmo tempo, apresentar o processo da modelagem [...]", e a pesquisa, "[...] em que orientamos os estudantes a modelar" (BIEMBENGUT, 2014, p. 41). Segundo a autora, tanto o ensino como a pesquisa estão presentes nas fases do processo de modelação.

$O$ terceiro questionamento tem relação com 0 professor que se propõe trabalhar com Modelagem, ou seja, como aprender para ensinar matemática por meio de modelos? A autora sugere que é preciso aprender para ensinar, e deve ensinar para aprender.

Com o fim de aprender para ensinar, a sugestão é primeiro analisar modelos prontos e processos de construção de modelos, com objetivo de identificar dados, conteúdos matemáticos, conteúdos não matemáticos, pré-requisitos desses conteúdos. Quanto ao ensinar para aprender, a sugestão é que se comece aplicando modelos, traduzindo-os de forma didática, estabelecendo objetivos claros nas aplicações. Também contextualizar o modelo com as ideias e conceitos essenciais, elaborar questões que conduza ao conteúdo pretendido, formular problemas e situações-problema que levem ao conteúdo curricular, elaborar exemplos análogos com outras aplicações, etc.

Por fim, o quarto questionamento apresentado é: que possibilidades e dificuldades surgem para a implementação da modelagem na Educação? Segundo a autora, as possibilidades de implementação podem ocorrer de forma gradativa, conforme a segurança e experiência do professor, ou seja, 
primeiramente por meio de um modelo-guia e depois, conforme vai adquirindo-se mais segurança, o trabalho propriamente dito de modelagem.

Com o modelo-guia, Biembengut afirma que os estudantes podem ter "[...] melhor compreensão dos conteúdos curriculares e não curriculares desenvolvidos" (2014, p. 52), instigando o interesse pelos assuntos que são aplicados na realidade. Ao professor, permite conduzir as aulas de modo direcionado, permitindo que ele possa prever/determinar o tempo para ensinar os conteúdos curriculares. Este tem a oportunidade de "[...] apresentar exemplos análogos, retornar ao modelo-guia, resolvendo, avaliando e validando o modelo juntamente com os estudantes" (BIEMBENGUT, 2014, p. 53).

Já $\bigcirc$ trabalho de modelagem propriamente dito, que os estudantes realizam, pode conduzí-los a

"[...] atuar/fazer e não apenas 'aceitar' sem compreender o significado do que está estudando, fazer pesquisa, aprimorar o conhecimento e os sensos criativo e crítico, especialmente na formulação e validação do modelo" (BIEMBENGUT, 2014, p. 53).

Além disso, contribui para que os estudantes possam interagir e inteirarse "[...] dos trabalhos dos demais grupos no seminário, e, dentre outras atividades, aplicar as normas dos procedimentos científicos ao elaborar uma exposição escrita do trabalho" (BIEMBENGUT, 2014, p. 53). Assim, o professor pode acompanhar mais atentamente tanto as dificuldades quanto $O$ desenvolvimento do trabalho dos estudantes, ao mesmo tempo em que os orienta, tendo a oportunidade de avaliar o aprendizado deles, não somente em relação aos conteúdos curriculares.

A autora finaliza, destacando que também há dificuldades na implementação da Modelagem na Educação. Segundo a autora, para o professor, essas dificuldades ocorrem já na interpretação do contexto, pela falta de aperfeiçoamento, de planejamento, de disponibilidade para aprender e orientar e pela falta de apoio da comunidade, que não sabe como avaliar. Para o estudante, também a interpretação do contexto é uma dificuldade, e a disponibilidade para atividades extraclasse. A escolha 
do tema também é quase sempre uma questão difícil, além do trabalho em grupo (BIEMBENGUT, 2014).

Portanto, a Modelagem na Educação é defendida por Biembengut, pois entende que, como método, potencializa tanto o ensino quanto a pesquisa em sala de aula. Embora, tenha consciência que esta não seja a resposta para todos os problemas das práticas escolares no que diz respeito ao ensino e aprendizagem de Matemática. Porém, pode proporcionar aos estudantes e ao professor valores culturais e alguns princípios gerais concernentes ao papel desempenhado por eles na sociedade em que estão inseridos.

\section{2 (P2) - Modelagem Matemática sob um olhar de Educação Matemática e suas implicações para a construção do conhecimento matemático em sala de aula}

Esta publicação é um artigo da Revista de Modelagem na Educação Matemática, de 2010. O autor, Dionísio Burak (UEPG e UNICENTRO), possui Graduação em Matemática pelo UNICENTRO (1973), Especialização pela UNIOESTE (1976), Mestrado em Educação Matemática pela UNESP (1987) e Doutorado em Educação pela UNICAMP (1992). Sua principal área de atuação é Educação Matemática com foco em Modelagem Matemática.

Para uma síntese, a publicação pode ser apresentada nos seguintes tópicos: 1) Uma perspectiva de Educação Matemática 2) A Modelagem na perspectiva da Educação Matemática 3) Etapas da Modelagem Matemática.

Em primeiro lugar, Burak apresenta uma perspectiva de Educação Matemática, o que já havia feito em Burak e Klüber (2008). Sua concepção se baseia no modelo do tetraedro de Higginson, por meio do qual a natureza da Educação Matemática é percebida como se fosse um tetraedro, sendo cada face, uma das áreas: Matemática, Filosofia, Psicologia e Sociologia. 
Figura 1: Tetraedro de Higginson

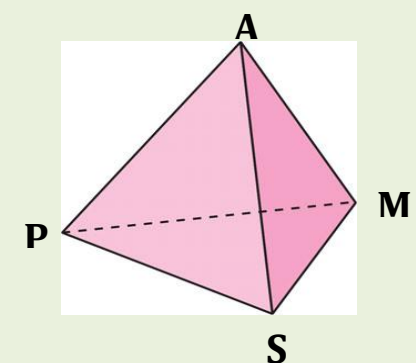

Fonte: Adaptado de Burak (2010, p. 13)

Assim, após fazer algumas considerações sobre a dinâmica da evolução nos campos da Psicologia e da Sociologia, propôs a inclusão de áreas como a Língua materna e a Antropologia por entender que esse novo modelo (Figura 2) possibilita melhor interação entre as diversas áreas do conhecimento, uma vez que a própria "[...] estrutura interna da Educação Matemática também se modificou" (BURAK, 2010, p.14). Há uma proposta de mudança de paradigma, de ampliação das áreas, conforme a representação indicada a seguir.

Figura 2: Concepção de Educação Matemática conforme Burak

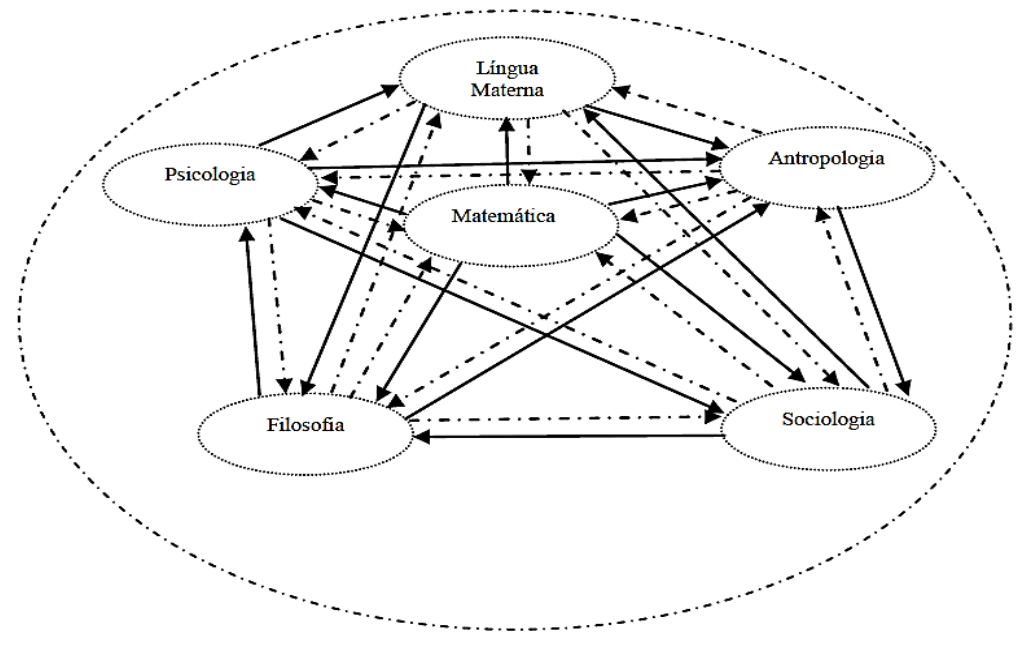

Fonte: Burak (2010, p. 14)

Burak ressalta, porém, que essa proposta não se coloca como uma concepção fechada, mas que indica possibilidades de expansão nas discussões sobre a natureza da Educação Matemática, considerando-a 
como Ciência Humana e Social. Nesse sentido, mais tarde Burak e Klüber (2013, p. 35) afirmam que essa perspectiva de Educação Matemática:

[...] permite considerar que a Matemática está condicionada à Educação e que, sob essa orientação, não é irrelevante fazer um ensino de Matemática, considerando-se contribuições da área da Educação, ou seja, por bases epistemológicas que não sejam exclusivas da disciplina. [...] significa dizer que no ato de se ensinar Matemática faz-se necessário considerar os componentes indicados no modelo, para que se possa oportunizar uma aprendizagem mais efetiva por meio de um ensino mais consciente e crítico pelo professor, em relação ao complexo ato de ensinar, especificamente, Matemática.

Em segundo lugar, baseado em Burak (1992), o autor reafirma que, com foco principalmente para o Ensino Básico, a Modelagem Matemática configura-se nessa perspectiva como

"[...] um conjunto de procedimentos, cujo objetivo é estabelecer um paralelo para tentar explicar, matematicamente, os fenômenos presentes no cotidiano do ser humano, ajudando-o a fazer predições e a tomar decisões" (BURAK, 1992, p. 62).

De acordo com o autor, a concepção de Modelagem vista no contexto das Ciências Humanas e Sociais, deve proporcionar atividades que consideram os sujeitos, o ambiente social, o ambiente cultural e outras variáveis. Nessa perspectiva, os conteúdos matemáticos passam a dividir a importância com outros conceitos não necessariamente matemáticos, como Burak já havia frisado:

[...] a construção do modelo pode propiciar o contato com vários conceitos conhecidos e também a oportunidade de construir novos conceitos. Esses conceitos podem não ser, somente, conceitos matemáticos. Também os conceitos usados na área específica do assunto tratado acabam por enriquecer a experiência vivida pelo grupo, através do método da Modelagem (BURAK, 1992, p.199).

Segundo Burak (1992, 2004), a concepção de Modelagem como prática educativa pressupõe os seguintes princípios para a sua adoção: a) partir do interesse do grupo de pessoas envolvidas b) obter as informações e os dados no ambiente onde localiza-se o interesse do grupo. 
O autor destaca que esse interesse pode ser tanto num sentido positivo, como elementos ou fatos que trazem benefícios, vantagens ou sensações agradáveis quanto, num sentido negativo, como questões que trazem inquietação, transtorno e levam ao desejo de resolvê-las (BURAK, 2010).

A ideia de modelo matemático, para Burak (2010), refere-se a uma representação em linguagem matemática, geralmente sob a forma de uma equação, inequação, sistema de equações, a planta baixa de uma casa ou um mapa, uma tabela. Até mesmo "[...] uma lista de preços em uma tabela, por exemplo, como capaz de ajudar na tomada de decisões" (BURAK; KLÜBER, 2013, p.42) pode ser considerada um modelo matemático. Segundo - autor, os modelos matemáticos têm como objetivo explicar matematicamente situações do cotidiano das pessoas, ajudando-as a fazer predições e tomar decisões.

Por fim, em terceiro lugar, para o desenvolvimento de atividade com Modelagem no contexto educacional, baseado em Burak $(1992,2004)$, o autor, sugere cinco etapas: 1) a escolha do tema 2) a pesquisa exploratória 3) o levantamento dos problemas 4) a resolução dos problemas e desenvolvimento do conteúdo matemático no contexto do tema 5) a análise crítica da solução.

A escolha do tema é a etapa na qual o professor incentiva e oferece condições para que os alunos possam escolher o tema sobre o qual realizarão a pesquisa. Aqui aparece o sentido antropológico da Educação Matemática, isto é, a ideia do 'conviver para dar conta do lugar', além da componente da Sociologia.

Na pesquisa exploratória os estudantes são encaminhados a procurar materiais e dados teóricos suficientes para embasar a pesquisa. Nesse momento há um fortalecimento do grupo e o desenvolvimento nos estudantes de uma atitude investigativa, contribuindo para que tome conhecimento da realidade em que está inserido. Além disso, é desenvolvida no estudante a formação de valores, atitudes e espírito crítico. 
O autor destaca, porém, que nessa etapa pode haver dificuldades para o estudante sair do ambiente escolar, o que pode ser contornado com o uso dos recursos tecnológicos.

No levantamento dos problemas os estudantes são convidados a apresentar todos os materiais e dados teóricos colhidos na etapa anterior, e começam a elaborar e esquematizar os problemas surgidos sobre o tema, passando a "[...] conjeturarem sobre tudo que pode ter relação com a Matemática, elaborando problemas simples ou complexos que permitam vislumbrar a possibilidade de aplicar ou aprender conteúdos matemáticos" (KLÜBER; BURAK, 2006, p. 4). Conforme o autor, nessa etapa aparece fortemente as componentes da Filosofia - "por quê", e da Psicologia, em que as atividades de coletar, organizar e elaborar implicam na percepção, apreensão e assimilação da realidade de acordo com as teorias cognitivas. Eles destacam ainda a diferença entre os problemas surgidos no processo de Modelagem, nas quais o estudante é autor, e os do livro didático, feito por outros.

$\mathrm{Na}$ resolução dos problemas e desenvolvimento do conteúdo matemático no contexto do tema, os estudantes são incentivados a buscar as condições necessárias para resolver os problemas propostos na etapa anterior, com o auxílio dos conteúdos matemáticos. Nessa etapa, o autor destaca que os problemas é que determinam o conteúdo, de modo que os estudantes têm a oportunidade de construírem modelos matemáticos (formação do pensar matemático), utilizando o ferramental matemático já disponível ou pode "criá-lo" para resolver os problemas. Neste caso, o autor percebe a componente importante da Psicologia da Educação (Matemática) para o processo de ensino e aprendizagem. Por fim, esse é o momento de ver a perspectiva da Matemática como Ciência e como Aplicação.

A análise crítica da solução é "[...] marcada pela criticidade, não apenas em relação à Matemática, mas também em relação a outros aspectos, como viabilidade e coerência das resoluções apresentadas" 
(KLÜBER; BURAK, 2006, p. 5). Conforme o autor, essa etapa proporciona ao estudante desenvolver pensamento crítico e argumentação lógica, oportunizando a discussão de aspectos relacionados à Matemática, à Sociedade, à Cultura, à Economia e à Política. Em síntese, é o momento em que se pode perceber a Modelagem no contexto da Educação Matemática como Ciência Humana e Social.

Assim, para Burak (2010) é preciso considerar a Modelagem Matemática a partir de uma visão múltipla da Educação Matemática como Ciência Humana e Social. Desse modo, segundo o autor, é possível ressaltar algumas de suas potencialidades, como prática educativa, ao trabalhá-la de modo a proporcionar interação entre Matemática e outras áreas do conhecimento que constituem a educação geral, visando o ensino e a aprendizagem num contexto mais amplo.

\section{3 (P3) - Modelagem Matemática: O que é? Por que? Como?}

Esta publicação é um artigo da revista Veritati, de 2004. O autor, Jonei Cerqueira Barbosa (UFBA), possui Graduação em Matemática (1997) e doutorado em Educação Matemática pela UNESP (2001). Sua ênfase de pesquisa é em Modelagem Matemática, e atua principalmente na análise das práticas dos alunos e dos professores no ambiente de Modelagem Matemática.

A síntese da publicação está dividida nos seguintes questionamentos: 1) o que é Modelagem Matemática? 2) por que usar Modelagem Matemática? 3) como aplicar Modelagem Matemática?

Em primeiro lugar, antes de expressar sua concepção de Modelagem, Barbosa apresenta algumas ideias iniciais. Primeiramente, coloca a noção de 'ambiente de aprendizagem' proposta por Skovsmose (2000), referindo-se "[...] às condições nas quais os alunos são estimulados a desenvolverem determinadas atividades. [...] diz respeito a um lugar ou espaço que cerca, envolve" (BARBOSA, 2001b, p. 6). 
Outra ideia refere-se aos conceitos de problematização e investigação, destacando que o primeiro tem a ver com a ação de "[...] criar perguntas e/ou problemas [...]", e o segundo refere-se "[...] à busca, seleção, organização e manipulação de informações e reflexão sobre elas" (BARBOSA, 2004, p. 3). Segundo o autor, essas duas atividades não são disjuntas, mas articuladas com o objetivo de propiciar aos estudantes um 'conhecimento reflexivo'.

Mais uma ideia que Barbosa (2004) discute é sobre a origem das atividades de Modelagem, considerando que essas não podem ser tomadas de situações fictícias, mas "[...] em situações cujas circunstâncias se sustentam no mundo social e não nas criadas (no sentido estrito da palavra) por alguém" (p.3). Devem ser atividades com 'referência na realidade' (SKOVSMOSE, 2000).

De acordo com Barbosa (2007), a utilização da expressão 'referência na realidade' sugere uma diferença em relação à expressão 'mundo real', ou seja, quando utiliza referência na realidade está concebendo a Matemática como parte da realidade. Mas por compreender que esta nomenclatura pode gerar uma dificuldade filosófica de compreensão, ultimamente adota as expressões 'situações do dia a dia, do mundo do trabalho e das ciências'.

De posse desses conceitos, Barbosa (2004, p. 3) define a Modelagem Matemática no contexto educacional como sendo

"[...] um ambiente de aprendizagem no qual os alunos são convidados a problematizar e investigar, por meio da matemática, situações com referência na realidade".

A ênfase dada pelo autor é desenvolver uma pesquisa, uma investigação, não necessariamente, chegar a um modelo. Nesta publicação, o autor não enfatiza sua concepção de modelo matemático. Ele indica, em Barbosa et al (2007, p. 161), que modelo matemático é "[...] qualquer representação matemática da situação em estudo [...]", no intuito 
de sinalizar que um modelo não precisa ser composto exclusivamente por equações ou inequações que representem relações entre variáveis.

Nesse sentido, Barbosa (2003) defende que os modelos matemáticos devem ser analisados numa perspectiva sociocrítica ${ }^{4}$ da Modelagem Matemática, isto é, discutir o papel e a natureza dos modelos matemáticos na sociedade, apoiando-se na 'Educação Matemática Crítica' (SKOVSMOSE, 1994)5. Para Barbosa, os modelos matemáticos têm uma 'função social' quando destaca que estes desenvolvem um papel na sociedade como balizadores de decisões, de modo que "[...] faz-se necessário ultrapassar as dimensões técnicas da Modelagem e realizar uma análise crítica do papel dos modelos matemáticos na vida social" (BARBOSA, 2001a, p. 19).

Em segundo lugar, é discutido pelo autor, o porquê do uso da Modelagem Matemática no contexto educacional. Ele destaca vários argumentos legítimos e importantes como: motivação, facilitação da aprendizagem, preparação para utilizar a matemática em diferentes áreas, desenvolvimento de habilidades gerais de exploração e compreensão do papel sociocultural da matemática. Porém, enfatiza este último argumento, por entender que este

"[...] está diretamente conectado com o interesse de formar sujeitos para atuar ativamente na sociedade e, em particular, capazes de analisar a forma como a matemática é usada nos debates sociais" (BARBOSA, 2004, p.2).

Nesse sentido, Barbosa (2001b, p. 5) destaca "[...] que as atividades devem potencializar a reflexão sobre a matemática, a própria Modelagem e seu significado social", ou seja, o interesse aqui é, conforme o autor, "[...]

\footnotetext{
4 As atividades de Modelagem são consideradas com oportunidades para explorar os papéis que a matemática desenvolve na sociedade contemporânea. Nem Matemática nem Modelagem são "fins", mas sim "meios" para questionar a realidade vivida (BARBOSA, $2001 b$, p.4).

${ }^{5}$ SKOVSMOSE, O. Reflective knowledge: its relation to the mathematical modellig process. Int.

J. Math. Educ. Sci. Technol., London, v. 21, n. 5, p. 765-779, 1990.
} 
envolver os alunos na reflexão sobre a presença da matemática na sociedade, a organização e condução das atividades" (2003, p.7).

Portanto, quanto às implicações para os currículos de Matemática, é acertada sua afirmação:

\begin{abstract}
"Mais do que informar matematicamente às pessoas, é preciso educar criticamente através da matemática. Essa dimensão ultrapassa os limites intrínsecos da matemática e volta-se para a preocupação do ser-sujeito pela matemática" (BARBOSA, 2001a, p.22).
\end{abstract}

Por fim, em terceiro lugar, o autor discute como implementar a Modelagem nas aulas de matemática. Com base nos trabalhos de Galbrith 1995)6, em que refere 'níveis de modelagem', Barbosa propõe o que chama de 'regiões de possibilidades' ou simplesmente 'casos'.

Dessa forma, para o desenvolvimento de tarefas de Modelagem, Barbosa (2004) considera que esse processo deve proporcionar, de acordo com o que é visto na tradição brasileira, os seguintes momentos: elaboração da situação-problema; simplificação; dados qualitativos e quantitativos; e, resolução. Assim, para a implementação da Modelagem nas aulas de matemática, Barbosa (2004) propõe três "casos", conforme a participação do professor e dos estudantes no processo.

Quadro 1 - O estudante e o professor nos casos de Modelagem

\begin{tabular}{|l|l|l|l|}
\hline \multicolumn{1}{|c|}{ TAREFAS REALIZADAS } & \multicolumn{1}{c|}{$\mathbf{1}^{\circ}$ CASO } & \multicolumn{1}{c|}{$\mathbf{2}^{\circ}$ CASO } & \multicolumn{1}{c|}{$\mathbf{3}^{\circ}$ CASO } \\
\hline Elaboração da situação-problema & prof. & prof. & prof./estud. \\
\hline Simplificação & prof. & prof./estud. & prof./estud. \\
\hline Dados qualitativos/quantitativos & prof. & prof./estud. & prof./estud. \\
\hline Resolução & prof./estud. & prof./estud. & prof./estud. \\
\hline
\end{tabular}

Fonte: Elaborado pelos autores de acordo com (BARBOSA, 2004, p.5)

Desse modo, o autor destaca que esses "casos" devem ser desenvolvidos tendo bem claro que "[...] estão subordinados à compreensão de Modelagem [conforme a concepção proposta], [...] mas

6 GALBRAITH, P. Modelling, teaching, reflecting - what I have learned. In: SLOYER, C. et al. Advances and perspectives in the teaching of Mathematical modelling and Applications. Yorklyn, DE: Water Street Mathematics, 1995. p. 21-45. 
que ilustram a flexibilidade da Modelagem nos diversos contextos escolares" (BARBOSA, 2004, p. 4).

Assim, Barbosa conclui, afirmando que sua concepção sobre Modelagem Matemática no âmbito educacional parte de uma perspectiva crítica, por meio da qual enfatiza a problematização e investigação, tendo como situações de estudo aquelas com referência na realidade, ou seja, em situações do dia a dia, do mundo do trabalho e das ciências. Por fim, propõe três casos, como possibilidades para o trabalho com Modelagem conforme o papel do professor e os estudantes.

\section{ANÁLISE DAS CONVERGÊNCIAS E DIVERGÊNCIAS}

Para a análise, foram consideradas as concepções de Biembengut, Burak e Barbosa. Os aspectos que direcionaram a análise no que diz respeito às convergências e/ou divergências foram: $O$ que é modelo? O que é Modelagem? Por que Modelagem? Como implementar Modelagem?

De acordo com as sínteses, percebe-se convergência nas três produções quanto à concepção de modelo, pois descrevem-no de diferentes formas com uma base comum: uma representação matemática de uma dada situação do mundo real. Quanto à forma de representar o modelo, Biembengut e Burak convergem, destacando que pode ser por meio da simbologia aritmética e algébrica da Matemática, além de tabelas, desenhos, gráficos, mapas, maquetes, etc. Barbosa não deixa explícita essa representação. As três produções também convergem em relação ao papel social que os modelos têm a desempenhar, seja em resolver o problema inicial, em prever fenômenos ou em ajudar na tomada de decisões.

Sobre a concepção de Modelagem, percebe-se que há certa convergência entre todos os autores no aspecto relacionado a partir do interesse do grupo, embora essa proximidade fique mais evidente entre Burak e Barbosa. Para Biembengut o desenvolvimento do conteúdo curricular deve determinar os problemas, divergindo de Burak e Barbosa que entendem o contrário, isto é, os problemas é que devem determinar o 
conteúdo a ser estudado, rompendo assim com uma visão linear do currículo. Vale ressaltar que Biembengut defende a ideia de escolher temas que tratem dos conteúdos programáticos que facilitem a adoção da Modelagem pelos professores.

Tanto Burak quanto Barbosa, defendem a não obrigatoriedade da construção de um modelo no processo de Modelagem, divergindo de Biembengut, que pela própria concepção admite a construção.

Ainda sobre a concepção de Modelagem, as três produções consideram como parte da Modelagem o desenvolvimento de pesquisa (problematização e investigação) pelos estudantes, a interdisciplinaridade, a criatividade, a capacidade de prever e tomar decisões no contexto social em que estão inseridos.

Em relação a questão, Por que Modelagem no Ensino?, todos pensam na mesma direção. Destacam que a Modelagem possibilita ensinar o conteúdo matemático, desenvolver pesquisa, promover a criatividade do estudante, dar maior aplicabilidade à Matemática, contextualizando os conteúdos matemáticos no âmbito social, econômico e cultural. Além disso, promove a interdisciplinaridade, instiga o interesse nos estudantes e favorece o trabalho em grupo.

Por fim, no aspecto relacionado à implementação da Modelagem no contexto da sala de aula, todos os autores comungam da mesma ideia ao sugerir o trabalho em grupo, e os três sugerem etapas. Essas etapas recebem nomes diferentes em cada uma das concepções, porém se desenvolvem de forma convergente. Percebe-se uma certa aproximação entre Biembengut e Barbosa, quanto ao trabalho inicial com Modelagem. Biembengut propõe que o professor iniciante com a Modelagem comece estudando, analisando e aplicando modelos prontos junto com os alunos. Já Barbosa propõe três casos de Modelagem, conforme a atuação do professor e do estudante, de modo que o primeiro caso nos estudos de Barbosa se aproxima do trabalho inicial com Modelagem proposto por Biembengut. 
Assim, diante dessa análise com respeito às convergências e divergências percebidas nesses três autores, retomam-se as questões iniciais: Que convergências e divergências emergem na comparação entre as principais concepções de Modelagem de Biembengut, Burak e Barbosa? Levando em conta essas convergências e divergências, de que modo o uso de Modelagem pode favorecer o processo de ensino e aprendizagem com enfoque na pesquisa em sala de aula como princípio pedagógico?

Com relação a primeira questão, percebe-se que há convergências: dos três autores em relação a concepção de modelo; de Biembengut e Burak na representação de modelo; dos três na concepção de Modelagem relacionada à pesquisa, interesse do grupo, interdisciplinaridade, criatividade e tomada de decisões; de Burak e Barbosa na não obrigatoriedade de construção de modelo; dos três na questão do por quê Modelagem e também com relação ao trabalho em grupo; de Biembengut e Barbosa na questão relacionada ao trabalho inicial com Modelagem. Já as divergências são percebidas entre Biembengut, para quem o conteúdo determina os problemas, e os outros dois autores, para quem os problemas é que determinam os conteúdos; Biembengut também diverge de Burak e Barbosa com relação a obrigatoriedade da construção de modelo. Biembengut defende a construção de modelo, enquanto Burak e Barbosa, não defendem como uma prioridade.

Assim, com relação à segunda questão, considerando que as convergências apontam para a mesma direção do trabalho com pesquisa em sala de aula, partindo do interesse do estudante, contribui para o seu desenvolvimento da consciência crítica e questionadora, criatividade, bem como do desenvolvimento do conteúdo matemático num contexto de reflexão social, cultural e política, proporcionado pela interdisciplinaridade; e as divergências podem ser analisadas no sentido de escolher o melhor modo de integrá-la no contexto da pesquisa em sala de aula, sendo possível defender que o uso da Modelagem pode ser um grande aliado no contexto da pesquisa em sala de aula no que diz respeito a favorecer o processo de 
ensino e aprendizagem, não só de matemática, mas também das outras Ciências.

\section{CONSIDERAÇÕES FINAIS}

Partindo da investigação sobre os principais pontos referentes à Modelagem no contexto educacional de três publicações, a saber, P1) Modelagem Matemática na Educação em sua essência (BIEMBENGUT, 2014); P2) Modelagem Matemática sob um olhar de Educação Matemática e suas implicações para a construção do conhecimento matemático em sala de aula (BURAK, 2010); e, P3) Modelagem Matemática: O que é? Por que? Como? (BARBOSA, 2004), foi feita uma análise em relação às convergências e divergências nessas publicações, considerando os seguintes aspectos: O que é modelo? O que é Modelagem? Por que Modelagem? Como Modelagem?

Tendo como enfoque perceber aspectos relativos às convergências e divergências emergentes na comparação das concepções de Modelagem escolhidas, buscou-se compreender um pouco sobre seus principais aspectos e assim poder refletir sobre como o uso de Modelagem pode favorecer os processos de ensino e aprendizagem com enfoque na pesquisa em sala de aula como princípio pedagógico.

Após fazer a análise dos aspectos citados, pôde-se perceber que as três publicações sinalizam convergência nos aspectos mais importantes em relação à concepção do trabalho com Modelagem, propiciando assim, a integração desta com alguns aspectos da pesquisa em sala de aula, de modo que é possível apontar uma aproximação das três concepções de Modelagem na Educação para um favorecimento do processo ensino e aprendizagem de Matemática e de outras Ciências.

Portanto, toda a discussão levantada neste trabalho tem por finalidade, incentivar o aprofundamento do assunto sobre Modelagem no contexto da pesquisa em sala de aula. O objetivo último, de certo modo, é articular a 'integração' das concepções apresentadas, contribuindo para 
que possam ser colocadas em prática nas salas de aula e favoreçam, pelo menos em parte, na qualidade no ensino, principalmente na Educação Básica.

\section{REFERÊNCIAS}

ALMEIDA, L. M. W.; SILVA, H. C. A Matematização em Atividades de Modelagem Matemática. Alexandria Revista de Educação em Ciência e Tecnologia, v. 8, n.3, p. 207-227, novembro 2015.

BARBOSA, J. C. A prática dos alunos no ambiente de Modelagem Matemática: o esboço de um framework. In: BARBOSA, J. C.; CALDEIRA, A. D.; ARAÚJO, J. L. (Org.). Modelagem Matemática na Educação Matemática Brasileira: pesquisas e práticas educacionais. Recife: SBEM, 2007. p.161-174.

BARBOSA, J. C. Modelagem Matemática e a perspectiva sociocrítica. In: Seminário Internacional de Pesquisa em Educação Matemática, 2., 2003, Santos. Anais... São Paulo: SBEM, 2003. 1 CD-ROM.

BARBOSA, J. C. Modelagem Matemática: concepções e experiências de futuros professores. Tese (Doutorado em Educação Matemática). Universidade Estadual Paulista Júlio de Mesquita Filho, UNESP, Rio Claro, 2001a.

BARBOSA, J. C. Modelagem na Educação Matemática: contribuições para o debate teórico. In: Reunião Anual da ANPED, 24., 2001, Caxambu. Anais... Rio de Janeiro: ANPED, 2001b. 1 CD-ROM.

BARBOSA, J. C. Modelagem Matemática: O que é? Por quê? Como? Veritati, Salvador, n. 4, p. 73-80, 2004.

BASSANEZI, R. C. Ensino-aprendizagem com modelagem matemática: uma nova estratégia. São Paulo: Contexto, 2002.

BIEMBENGUT, M. S. 30 Anos de Modelagem Matemática na Educação Brasileira: das Propostas primeiras às propostas atuais. Alexandria - Revista de Educação em Ciência e Tecnologia, v. 2, p. 7-32, 2009.

BIEMBENGUT, M. S. Modelagem Matemática como Método de Ensino Aprendizagem de Matemática em cursos de $1^{\circ}$ e $2^{\circ}$ graus. Dissertação de Mestrado. Universidade Estadual Paulista Júlio de Mesquita Filho, UNESP, Brasil, 1990.

BIEMBENGUT, M. S. Modelagem matemática no ensino fundamental. Blumenau: Edifurb, 2014.

BIEMBENGUT, M. S.; HEIN, N. Modelagem matemática no ensino. 3. ed. São Paulo: Contexto, 2003. 
BONOTTO, D. L.; LARA, I. C. M. Modelagem Matemática e formação continuada de professores: um mapeamento teórico. In: VI Congresso Internacional de Ensino da Matemática, 2013. Anais... Canoas: ULBRA, 2013.

BURAK, D. Modelagem Matemática e a Sala de Aula. In: Encontro Paranaense da Modelagem na Educação Matemática, I, Londrina, 2004. Anais... Londrina: UEL, p. 1-11, 2004.

BURAK, D. Modelagem Matemática: ações e interações no processo de ensino-aprendizagem. Tese (Doutorado em Educação). Universidade Estadual de Campinas. Campinas, 1992.

BURAK, D. Modelagem Matemática sob um olhar de Educação Matemática e suas implicações para a construção do conhecimento matemático em sala de aula. Revista de Modelagem na Educação Matemática (FURB), v. 1 , n. 1, p. 10-27, 2010.

BURAK, D.; KLÜBER, T. E. Considerações sobre modelagem matemática em uma perspectiva de Educação Matemática. Margens (UFPA), v. 6, p. 33-50, 2013.

BURAK, D.; KLÜBER, T. E. Educação Matemática: contribuições para a compreensão de sua natureza. Acta Scientiae (ULBRA), v. 10, jul-dez, 2008. p. 93-106.

CARGNIN-STIELER, M.; BISOGNIN, V. Contribuições de metodologia da modelagem matemática para cursos de formação de professores. Revista Iberoamericana de Educación, n. 49/3, 2009.

CHAVES, M.I.A.; ESPIRITO SANTO, A. O. Modelagem Matemática: uma concepção e várias possibilidades. Bolema - Boletim de Educação Matemática. Ano 21, n.30. Rio Claro: UNESP, 2008.

KLÜBER, T. E.; BURAK, D. Concepções de modelagem matemática: contribuições Teóricas, In: Educação Matemática Pesquisa, São Paulo, v. 10, n. 1, pp. 17-34, 2008.

KLÜBER, T. E.; BURAK, D. Discutindo algumas aproximações epistemológicas evidenciadas nos depoimentos dos alunos em relação à Modelagem Matemática. In: ANPED SUL, VI, Santa Maria, 2006. Anais... Santa Maria: Novas Questões, p. 1-6, 2006.

MEYER, J. F. C. A; CALDEIRA, A.D; MALHEIROS, A.P.S. Modelagem em Educação Matemática. Belo Horizonte: Autêntica, 2011.

MORAES, R.; GALLIAZZI, M. C.; RAMOS, M. G. Pesquisa em sala de aula: fundamentos e pressupostos. In: MORAES, R.; LIMA, V. M. R. (Org.). Pesquisa em sala de aula: tendências para a educação em novos tempos. 3. ed. Porto Alegre: EDIPUCRS, 2012.

SKOVSMOSE, O. Cenários para investigação. Bolema - Boletim de Educação Matemática, Rio Claro, ano 13, n. 14, p. 66-91, 2000. 
TAMBARUSSI, C. M.; KLÜBER, T. E. Focos da pesquisa stricto sensu em Modelagem Matemática na Educação Matemática brasileira: considerações e reflexões. Educação Matemática Pesquisa. São Paulo, v. 16 , n. 1, 2014, p. 209-225.

TAMBARUSSI, C. M.; KLÜBER, T. E. Modelagem Matemática na Educação Matemática: O que se tem pesquisado? In: Conferência Nacional sobre Modelagem na Educação Matemática, 8, 2013. Santa Maria. Anais... Santa Maria: Centro Universitário Franciscano, 2013. v.1, p. 1-15.

Recebido em: Março de 2017 Aprovado em: Setembro de 2017 